\title{
PREDICTORS OF TREATMENT OUTCOME IN PATIENTS WITH INTERSTITIAL LUNG DISEASES IN A TERTIARY CARE CENTRE
}

Ronaldwin $B^{1}$, Kamala $R^{2}$

${ }^{1}$ Additional Professor, Department of Pulmonary Medicine, Government Medical College, Trivandrum.

2Junior Consultant (Chest and TB), Chest Diseases Hospital, Pulayanarkotta, Trivandrum.

ABSTRACT

Interstitial lung diseases represent a large group of more than 200 different entities. Interpretation of clinically relevant disease features and surrogate markers of disease activity can help predict the short- and long-term outcome of patients with interstitial lung diseases.

\section{PRIMARY OBJECTIVE}

To identify the clinico-radiological characteristics influencing the successful outcome of treatment of interstitial lung diseases in a tertiary care centre.

\section{SECONDARY OBJECTIVE}

To find out the pattern of interstitial lung disease in our setting.

\section{METHODOLOGY}

This is a prospective observational study done in the Department of Respiratory Medicine, Medical College, Thiruvananthapuram, from July 2005 to May 2007. The study population included patients with ILD attending the Department of Respiratory Medicine. Sample size was calculated as 71. Outcome variables were defined according to ATS Guidelines 2000. Patients were diagnosed and classified as per international guidelines and treatment started accordingly. Patients were followed up every 3 months or as required by clinical assessment for a minimum of 3 months and a maximum of 18 months.

\section{RESULTS}

A total of 120 patients (58 males and 62 females) were included in the study. 15 patients (12.5\%) were lost to followup. Out of 120 patients in the study, $55 \%$ had a favourable/stable outcome while $45 \%$ had a poor outcome, which included unfavourable response, death, and lost to followup. Factor analysis of our data showed that persons who are not current smokers and nonsmokers have better outcome. Other predictors of successful outcome in order of significance included absence of honeycombing on HRCT, no history of alcoholism, female gender, absence of clubbing, age <50 years, no past anti-TB treatment and a reticulonodular pattern on chest $\mathrm{x}$ ray.

\section{KEYWORDS}

Interstitial Lung Disease, Predictors, Treatment Outcome

HOW TO CITE THIS ARTICLE: Ronaldwin B, Kamala R. Predictors of treatment outcome in patients with interstitial lung diseases in a tertiary care centre. J. Evolution Med. Dent. Sci. 2016;5(61):4312-4315, DOI: 10.14260/jemds/2016/984

\section{INTRODUCTION}

Interstitial lung diseases represent a large group of more than 200 different entities with an estimated prevalence 74.1 per 105 and incidence $28.8 \times 105$ per year and accounts for about $15 \%$ of respiratory practice. Prevalence of undiagnosed interstitial lung disease is 10 times that of clinically diagnosed cases.(1).Clinically different interstitial lung diseases have similar presentations, but varying prognosis with available treatment.(2) Interpretation of clinically relevant disease features and surrogate markers of disease activity can help predict the short- and long-term outcome of patients with interstitial lung diseases.(3)

\section{Financial or Other, Competing Interest: None}

Submission 30-05-2016, Peer Review 19-07-2016,

Acceptance 25-07-2016, Published 01-08-2016.

Corresponding Author:

Dr. Ronaldwin $B$,

Additional Professor,

Pulmonary Medicine,

Govt. Medical College,

Trivandrum.

E-mail: ronaldwin_b@yahoo.co.in

DOI: $10.14260 /$ jemds/2016/984

\section{Primary Objective}

To identify the clinico-radiological characteristics influencing the successful outcome of treatment of Interstitial Lung diseases in a tertiary care centre.

\section{Secondary Objective}

To find out the pattern of interstitial lung disease in our setting.

\section{Study Design}

Prospective observational study.

\section{Study Period}

July 2005 to May 2007.

\section{Study Setting}

Department of Respiratory Medicine, Medical College, Thiruvananthapuram.

\section{Study Population}

Patients with interstitial lung disease attending the Department of Respiratory Medicine, Medical College Hospital, Thiruvananthapuram. 


\section{Inclusion Criteria}

Patients diagnosed as interstitial lung diseases based on clinical, radiological, and pulmonary function tests were included in the study.

\section{Exclusion Criteria}

Disease that may affect the interstitium like miliary TB, malignancies, pulmonary oedema, and viral pneumonias were excluded.

\section{Sample Size}

Sample size was calculated as 71 using the formula for comparison of two proportions:

\section{Outcome Variables}

Outcome variables were defined according to ATS guidelines 2000.(3)

\section{Successful:}

i. Favourable response to therapy.

ii. Presumed favourable/stable response to therapy.

\section{Poor}

Unfavourable response to therapy.

\section{Data Collection}

Data collection was done by using a proforma with structured questionnaire.

\section{Manoeuvre}

Baseline evaluation included: History, Clinical examination, Radiology, Chest x-ray, HRCT, Pulmonary function tests including ventilatory function test, Blood gas analysis, 6minute walk test, and other relevant investigations like ECG, Echo, Mantoux, Connective tissue disease workup, Blood investigations, etc.

Patients were diagnosed and classified as per international guidelines and treatment started accordingly. $(1,2,3)$
Patients were followed up every 3 months or as required by clinical assessment for a minimum of 3 months and a maximum of 18 months.

\section{RESULTS}

A total of 120 patients were included in the study. $77.5 \%$ of patients belonged to low socio-economic status. 15 patients $(12.5 \%)$ were lost to follow up. There were 4 patients (3.3\%) with a family history of ILD. Out of 58 males in the study group, 46 (79.3\%) were smokers and of this 40 (69\%) were current smokers. $74.1 \%$ males in the study group were alcoholics. Agricultural workers (12.5\%), construction workers $(10.8 \%)$, and factory workers $(9.2 \%)$ constituted the majority of employed persons. $46.7 \%$ patients had more than 12 months duration of symptoms and majority had advanced grades of dyspnoea. Extrapulmonary symptoms were present in 10 patients $(8.3 \%)$ of which skin and joint manifestations were most common. 22 patients (18.3\%) had haemoptysis.

The most common clinical signs on examination were clubbing (74.2\%) and bilateral inspiratory crackles (97\%). Hyperinflation on chest $\mathrm{x}$ ray was observed in 18 patients (15\%). Ventilatory lung function tests revealed a restrictive defect in $70(58.3 \%)$ patients and a mixed pattern in 50 $(41.7 \%)$ patients. Reversibility was observed in 12 patients (10\%). 2D echo was done in patients with clinical or ECG findings showing evidence of pulmonary hypertension (78 patients, $65 \%$ ) of which 51 patients (42.5\%) had evidence of PAH. LV dysfunction was observed in 7 patients (5.8\%). Only a very small proportion of patients had baseline ABG done.

Of the 105 patients followed up, 35 (29.2\%) have died. Prior to treatment, only $5.8 \%$ of the study group had an FVC $>60 \%$ whereas after treatment $32.5 \%$ has FVC $>60 \%$. Poor response (unfavourable outcome) was observed in $32 \%$ of patients who were treated with steroids and other drugs as per existing guidelines. Most common diagnosis in those who died was IPF (48.6\%). 64 (53.3\%) patients had deranged blood sugar levels during/after treatment compared to 27 (22.5\%) patients prior to treatment.

Age and Gender

\begin{tabular}{|c|c|c|c|c|c|c|c|c|c|}
\hline & $\mathbf{2 1 - 3 0}$ & $\mathbf{3 1 - 4 0}$ & $\mathbf{4 1 - 5 0}$ & $\mathbf{5 1 - 6 0}$ & $\mathbf{6 1 - 7 0}$ & $\mathbf{7 1 - 8 0}$ & $\mathbf{8 1 - 9 0}$ & Total & $\mathbf{\%}$ \\
\hline Male & 2 & 6 & 10 & 15 & 19 & 6 & 0 & 58 & 48.3 \\
\hline Female & 1 & 13 & 19 & 16 & 10 & 2 & 1 & 62 & 51.7 \\
\hline Total & $\mathbf{3}$ & $\mathbf{1 9}$ & $\mathbf{2 9}$ & $\mathbf{3 1}$ & $\mathbf{2 9}$ & $\mathbf{8}$ & $\mathbf{1}$ & $\mathbf{1 2 0}$ & $\mathbf{1 0 0}$ \\
\hline
\end{tabular}

There were 58 males (48.3\%) and 62 females (51.7\%) in the study group of which $53.2 \%$ females were aged less than 50 years.

\section{HRCT Pattern}

\begin{tabular}{|c|c|c|}
\hline Pattern & No. of Patients & $\mathbf{\%}$ \\
\hline Septal Thickening & 115 & 95.8 \\
\hline Nodules & 99 & 82.5 \\
\hline Ground-glass opacities & 71 & 59.2 \\
\hline Honeycombing & 58 & 48.3 \\
\hline Cystic changes & 40 & 33.3 \\
\hline Lymphadenopathy & 8 & 6.6 \\
\hline Pleural Thickening & 11 & 9.2 \\
\hline
\end{tabular}

The most common HRCT finding was septal thickening (95.8\%).Honeycombing was observed in $48.3 \%$.
Diagnosis

\begin{tabular}{|c|c|c|}
\hline Diagnosis & No. of patients & $\mathbf{\%}$ \\
\hline IPF & 49 & 40.8 \\
\hline Allergic alveolitis & 20 & 16.7 \\
\hline BOOP/COP & 14 & 11.7 \\
\hline NSIP & 7 & 5.8 \\
\hline PSS & 7 & 5.8 \\
\hline Sarcoidosis & 6 & 5.0 \\
\hline Rh. arthritis & 4 & 3.3 \\
\hline SLE/MCTD & 3 & 2.5 \\
\hline LAM & 3 & 2.5 \\
\hline LCH & 4 & 3.3 \\
\hline DIP & 2 & 1.7 \\
\hline RBILD & 1 & 0.8 \\
\hline Total & $\mathbf{1 2 0}$ & $\mathbf{1 0 0}$ \\
\hline
\end{tabular}


The most common diagnosis in our setting was found to be IPF (40.8\%).

Final Outcome

\begin{tabular}{|c|c|c|}
\hline Outcome & No. of Patients & \% \\
\hline Successful & 66 & 55.0 \\
\hline Poor & 54 & 45.0 \\
\hline Total & $\mathbf{1 2 0}$ & $\mathbf{1 0 0}$ \\
\hline
\end{tabular}

Out of 120 patients in the study, 55\% had a favourable/stable outcome while $45 \%$ had a poor outcome, which included unfavourable response, death, and lost to follow up.

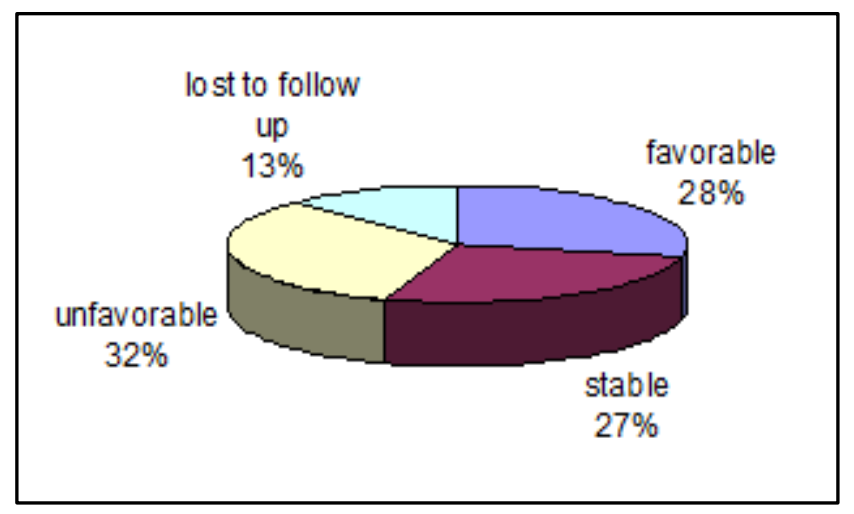

Univariate Analysis

(Factors Affecting Successful Outcome)

\begin{tabular}{|c|c|}
\hline Variable & p Value \\
\hline Age $<50$ years & 0.025 \\
\hline Female gender & 0.005 \\
\hline Nonsmoker & 0.011 \\
\hline Not a current smoker & 0.017 \\
\hline Not alcoholic & 0.032 \\
\hline No h/o anti-TB treatment & 0.033 \\
\hline No clubbing & 0.009 \\
\hline Reticulonodular radiological pattern & 0.005 \\
\hline No honeycombing in HRCT & 0.003 \\
\hline
\end{tabular}

Univariate analysis showed that patients aged $<50$ years, females, nonsmokers, and not current smokers, nonalcoholics with no past anti-TB treatment, no clubbing and with reticulonodular shadow and without honeycombing have successful outcome.

Logistic Regression

\begin{tabular}{|c|c|c|c|}
\hline Variable & $\begin{array}{c}\text { P } \\
\text { value }\end{array}$ & $\begin{array}{c}\text { Standard } \\
\text { Error }\end{array}$ & $\begin{array}{c}\text { Odds } \\
\text { Ratio }\end{array}$ \\
\hline Age <50 years & -0.172 & 0.215 & 0.842 \\
\hline Female gender & 0.789 & 0.776 & 2.2 \\
\hline Smoker & -0.371 & 1.018 & 0.690 \\
\hline Not a current smoker & 0.458 & 1.057 & 1.581 \\
\hline Not Alcoholic & -1.024 & 1.034 & 0.359 \\
\hline No h/o anti-TB treatment & -1.508 & 0.624 & 0.221 \\
\hline No clubbing & -1.356 & 0.781 & 0.258 \\
\hline $\begin{array}{c}\text { Reticulonodular } \\
\text { radiological Pattern }\end{array}$ & 1.057 & 0.67 & 2.878 \\
\hline $\begin{array}{c}\text { No honeycombing in } \\
\text { HRCT }\end{array}$ & -1.317 & 0.604 & 0.268 \\
\hline
\end{tabular}

Logistic regression revealed that the factors predicting a successful outcome of treatment include female gender, not a current smoker, presence of a reticulonodular radiological pattern.

\section{DISCUSSION}

Previous studies show that different clinico-radiological and pathophysiological characteristics influence the outcome in various interstitial lung diseases, but restricted themselves to ILD's with a particular aetiology.(4,5) Factors indicating a longer survival in IPF include a younger age $(<50$ years), female sex, shorter symptomatic period with less dyspnoea and relatively preserved lung function, presence of ground glassing and reticular opacities in HRCT, increased proportion of lymphocytes in BAL fluid, a beneficial/stable response to treatment at 3-6 months after initiation of treatment and a history of current smoking at the time of diagnosis. $(6,7,8)$ Factors associated with a poor outcome in BOOP include associated disorders, a predominantly interstitial pattern on imaging, a lack of lymphocytosis in BAL fluid and histopathologic finding of scarring and remodelling of the lung parenchyma in addition to organising pneumonia. $(9,10)$

Our study population included a heterogeneous group of ILD with varying aetiology. Logistic regression analysis of our data revealed that a female gender $(\mathrm{OR}=2.2)$, absence of current smoking (OR=1.581), and a reticulonodular radiological pattern $(\mathrm{OR}=2.878)$ were the significant factors predicting a successful outcome.(11,12)

Out of 58 males in the study group 46 (79.3\%) were smokers and of this 40 (69\%) were current smokers. Nonsmokers in the study group had a better outcome as per univariate analysis $(\mathrm{p}<0.011)$ and not being a current smoker was found to be statistically significant by univariate analysis $(\mathrm{p}<0.017)$ as well as a predictor of successful outcome. Previous studies on IPF have shown an increased incidence in smokers, but have suggested an improved survival in current smokers, the reason being unknown.(3,7)

In our study, female gender was identified as a factor for successful outcome by univariate analysis as well as on logistic regression analysis. Previous studies on IPF have identified female sex as a factor for good outcome. $(6,13)$

Presence of a reticulonodular pattern on radiology was found to be a significant influence on successful outcome by univariate analysis $(\mathrm{p}<0.005)$ and also a predictor of successful outcome. Presence of nodularity implies active disease due to inflammation and this maybe more steroid responsive than a predominantly reticular pattern, which suggests fibrosis.(14) According to previous studies, presence of ground glassing and reticular shadows in HRCT in IPF and nodular lesions in HP has been found to be a factor suggesting favourable outcome.(10,15)

Presence of a honeycombing pattern in radiology is an indicator of poor outcome and this also implies a delayed diagnosis. Delayed diagnosis and treatment leads to progression of fibrosis even in conditions with good response to timely therapeutic intervention. Hence, the study also shows the need for an increased awareness for identifying the disease early and initiating the appropriate treatment.(15)

\section{Relevance of the Study}

Out of the 120 patients, 31 (25.8\%) patients in the study population received anti-TB treatment and this has been 
shown to be an indicator of poor outcome probably due to a delay in proper diagnosis. So, patients with features of DPLDs and those who are empirically initiated on anti-TB treatment based on radiological suspicion should be followed up without fail to assess the progress and evaluation with HRCT and other relevant investigations must be done to rule out the possibility of ILD in cases, which do not respond.

\section{REFERENCES}

1. Coultas DB, Zumwalt RE, Black WC, et al. The epidemiology of interstitial lung disease. Am J Respir Crit Care Med 1994;150(4):967-972.

2. American Thoracic Society, European Respiratory Society, International Multidisciplinary Consensus. Classification of the idiopathic interstitial pneumonias. Am J Respir Crit Care Med 2002;165(2):277-304.

3. American Thoracic Society. Idiopathic pulmonary fibrosis: diagnosis and treatment. International consensus statement. American Thoracic Society (ATS) and the European Respiratory Society (ERS). Am J Respir Crit Care Med 2000;161(2 Pt 1):646-664.

4. King TE, Schwarz MI, Brown $\mathrm{K}$, et al. Idiopathic pulmonary fibrosis. Relationship between histopathologic features and mortality. Am J Repir Crit Care Med 2001;164(6):1025-1032.

5. BT Society, SO Committee. The diagnosis, assessment, and treatment of diffuse parenchymal lung disease in adults. Thorax 1999;54[Supp 1]:SI-28.

6. King TE, Tooze JA. Schwarz MI, et al. Predicting survival in idiopathic pulmonary fibrosis. Scoring system and survival model. Am J Respir Crit Care Med 2001;164(7):1171-1181.

7. Baumgartner KB, Samet J, Stidley CA, et al. Cigarette smoking: a risk factor for idiopathic pulmonary fibrosis. Am J Respir Crit Care Med 1997;155(1):242-248.
8. Walter N, Collard HR, King TE. Current perspectives on the treatment of idiopathic pulmonary fibrosis. Proc Am Thorac Soc 2006;3(4):330-338.

9. Yousem S, Lohr RH, Colby TV. Idiopathic bronchiolitis obliterans organising pneumonia/cryptogenic organising pneumonia with unfavourable outcome: pathologic predictors. Mod Pathol 1997;10(9):864-871.

10. Travis WD, Matsui K, Moss J, et al. Idiopathic nonspecific interstitial pneumonia: prognostic significance of cellular and fibrosing patterns: survival comparison with usual interstitial pneumonia and desquamative interstitial pneumonia. Am J Surg Pathol 2000;24(1):19-33.

11. Bjoraker JA, Ryu JH, Edwin MK, et al. Prognostic significance of histopathologic subsets in idiopathic pulmonary fibrosis. Am J Respir Crit Care Med 1998;157(1):199-203.

12. Jegal Y, Kim DS, Shim TS, et al. Physiology is a stronger predictor of survival than pathology in fibrotic interstitial pneumonia. Am J RespirCrit Care Med 2005;171(6):639-644.

13. Scadding JG, Hinson KFW. Diffuse fibrosing alveolitis (diffuse interstitial fibrosis of the lung): correlation of histology at biopsy with prognosis. Thorax 1967;22(4):291-304.

14. Flaherty KR, Mumford JA, Murray S, et al. Prognostic implications of physiologic and radiographic changes in idiopathic interstitial pneumonia. Am J RespirCrit Care Med 2003;168(5):543-548.

15. Nicholson AG, Colby TV, Dubois RM, et al. The prognostic significance of the histologic pattern of interstitial pneumonia in patients presenting with the clinical entity of cryptogenic fibrosing alveolitis. Am J Respir Crit Care Med 2000;162(6):2213-2217. 